\title{
Teacher Candidates' Use of Technology in Remedial Instruction at a Junior High School
}

\author{
Ya-Fung Chang, Chia-Ling Hsu, Wei-Nian Chen, and Tzu-Ting Wang
}

\begin{abstract}
To understand teacher candidates' use of technology while providing remedial instruction, we arranged field learning as part of a "Remedial Instruction" course. There were 11 participants. Data were collected from classroom observation journals, lesson plans and instructional materials, debriefing meeting records, reflective reports, and focus group interviews. The results indicate that teacher candidates' use of technology was influenced by their prior teaching experience, and that they often imitated the way in which the experienced remedial teacher used in class. Electronic presentations and videos were used most frequently. Through field learning, teacher candidates became more concerned about the main purpose of remedial instruction as well as the effectiveness of their technology use in class. Moreover, an expectation of technology use was made from "teacher presentation" to "facilitating students' self-learning" in the future. At the end, relevant suggestions are provided to enhance teacher candidates' abilities regarding the use of technology in remedial instruction.
\end{abstract}

Index Terms-Field learning, remedial instruction, teacher preparation, technology integration.

\section{INTRODUCTION}

In the current information society, it is crucial for teachers to know how to use technology effectively to facilitate student learning. In Taiwan, the Ministry of Education (MOE) has specified "Instructional Media and Operations" a required course for pre-service teachers. Moreover, many teacher education programs have offered an elective course "Computers and Instruction" to enhance pre-service teachers' technology competencies. However, such courses are often disassociated from the teaching field and their technology applications seldom focus on specific content area [1], [2]. Consequently, numerous scholars strongly suggest linking the university curriculum to the K-12 teaching field, and integrating authentic situations into university classrooms [3], [4].

Darling-Hammond (2006) also pointed out that there is a gap between theory-based knowledge provided by universities and experience-based knowledge acquired from

Manuscript received March 5, 2018; revised August 4, 2018. This work was supported in part by the Ministry of Science and Technology, Taiwan under Grant 105-2410-H-032-068.

Ya-Fung Chang and Chia-Ling Hsu are with Center for Teacher Education, Tamkang University, New Taipei City, Taiwan (e-mail: yfchang@mail.tku.edu.tw, clhsu@mail.tku.edu.tw).

Wei-Nian Chen is with the Department of Chinese Literature, Tamkang University, New Taipei City, Taiwan (e-mail: tzu360teacher1753will@gmail.com).

Tzu-Ting Wang is with Graduate Institute of Curriculum and Instruction, Tamkang University, New Taipei City, Taiwan (e-mail: sky99714@gmail.com). teaching in K-12 schools [5]. Thus, reform of teacher preparation is underway in various countries to diminish the gap between theory and practice [6], [7]. Conforming to this trend, the MOE in Taiwan has recently launched a policy that promotes at least 54-hour field learning for secondary teacher candidates before they undergo a half-year teaching practicum [8]. More specifically, teacher candidates are required to participate in activities such as classroom observation, teaching demonstration, remedial programs, and service learning in secondary schools. Research indicates that a combination of teacher training courses and field learning fosters positive attitudes toward teaching, and increases practical professional knowledge [9], [10]. Furthermore, teacher candidates' use of technology in authentic teaching situations helps transfer to their future teaching in K-12 schools [11], [12].

In this study, we investigated teacher candidates' use of technology in real-life settings of remedial instruction. The results provide valuable implications for teacher educators regarding how to assist teacher candidates to effectively integrate technology into remedial instruction. Specifically, three research questions were posed in this study:

1) Why did teacher candidates use technology when providing remedial instruction in class?

2) What were the characteristics of teacher candidates' use of technology in remedial instruction?

3) What were teacher candidates' reflections on the use of technology in remedial instruction from their field experience?

\section{PROCEDURE}

\section{A. Overview of the Course}

In response to the implementation of 12-year curriculum guidelines, our teacher educational program offers a two-credit course titled "Remedial Instruction." The course is offered in the spring semester for the second-year teacher candidates. The course has two sessions, either on the teaching subject of Chinese or that of English. The course aims to develop teacher candidates' abilities so that they are qualified to teach Chinese or English in remedial classes at junior high schools. The course involves an 18-hour training program specified by the MOE in Taiwan, and students who finish the program can obtain a remedial teacher certificate. The program covers the following topics: introduction to remedial instruction at junior high schools (2 hours), characteristics of low-achieving students and counseling (2 hours), classroom management in remedial instruction at junior high schools (2 hours), learning diagnosis and 
evaluation for low-achieving students ( 2 hours), teaching strategies for remedial students (4 hours), teaching materials and methods for remedial students (4 hours), and a case study of remedial teaching practices (2 hours) [13]. The MOE also issued a list of qualified lecturers to teach these topics.

The first author was responsible for the Chinese session during the spring semester of 2017. Two remedial teachers, Miss $\mathrm{H}$ and Miss $\mathrm{L}$ were invited to deliver lectures on the topics mentioned earlier. They also shared their lesson plans and digital materials regarding the use of technology in remedial classes on the Internet. Field learning was arranged to provide teacher candidates with practical exposure to the complexities of remedial instruction. For their mid-term assignments, the teacher candidates were asked to design a 45-minute lesson plan and instructional materials for remedial classes. Miss $\mathrm{H}$ was invited to review these assignments and to provide helpful feedback. For their final assignments, the teacher candidates were asked to observe at least two remedial classes and to write classroom observation journals for each class.

\section{B. Participants}

Thirty-five students enrolled in the first author's "Remedial Instruction" course in the spring semester of 2017. However, only 11 students participated in the field learning due to time constraints. Table I lists the demographic information of the 11 participants. Because S9, S10, and S11 had not undertaken the course "Chinese Teaching Materials and Methods," they collaborated with other participants and acted as assistants in the remedial teaching. Furthermore, S2's teaching subject was not Chinese. Therefore, he collaborated with S1 and acted as an assistant in the remedial teaching.

TABLE I: DEMOGRAPHIC DATA OF THE PARTICIPANTS $(N=11)$

\begin{tabular}{cccccc}
\hline \hline ID & Gender & $\begin{array}{c}\text { Educational } \\
\text { level }\end{array}$ & $\begin{array}{c}\text { Teaching } \\
\text { experience }\end{array}$ & $\begin{array}{c}\text { Demonstration } \\
\text { date }\end{array}$ & $\begin{array}{c}\text { As a teacher/ } \\
\text { assistant }\end{array}$ \\
\hline S1 & Female & Graduate & Yes & $3 / 14$ & teacher \\
\hline S2 & Male & Graduate & Yes & $3 / 14$ & assistant \\
\hline S3 & Female & Graduate & Yes & $5 / 23$ & teacher \\
\hline S4 & Female & Graduate & Yes & $6 / 6$ & teacher \\
\hline S5 & Female & Graduate & None & $4 / 10,4 / 24$ & teacher \\
\hline S6 & Male & Graduate & None & $3 / 27,3 / 28$, & teacher \\
\hline S7 & Male & Graduate & None & $5 / 16$ & teacher \\
\hline S8 & Female & Senior & None & $5 / 1,6 / 5$ & teacher \\
\hline S9 & Female & Junior & None & $5 / 23$ & assistant \\
\hline S10 & Female & Junior & None & $6 / 6$ & assistant \\
\hline S11 & Female & Junior & None & $6 / 6$ & assistant \\
\hline \hline & & & & & \\
\hline
\end{tabular}

\section{Field Learning in Remedial Instruction}

On the first day of the course, the students were informed that field learning was available. The field we selected for the course was a junior high school about a 10-minute walk to our campus. Miss W from that school volunteered to collaborate with us and allow our students to teach in her remedial class. There were 12 seventh grade students in her class. They met twice a week on Monday and Tuesday. Each session lasted 45 minutes. Three teacher candidates (S5, S6, and S8) joined the Monday session, and 10 teacher candidates joined the Tuesday session. Among them, S5 and S6 participated in both the sessions in a week.

The field learning began in March and was completed in June. We first observed Miss W's teaching demonstration in her remedial class. After the demonstration, she shared her remedial teaching experience with us, discussed the characteristics of her remedial students, and provided some helpful suggestions. In the following weeks, the participants took turns instructing the class under Miss W's supervision. The participant's teaching demonstration was followed by a debriefing meeting to obtain instant feedback from other participants and Miss W. The participants were asked to write classroom observation journals for each class, and to write reflective reports on their teaching demonstrations. On the last day of the course, a focus group interview was conducted to invite the participants to share their experiences, opinions, and suggestions about field learning.

\section{Data Collection and Analysis}

The data collected for this study included classroom observation journals, lesson plans and instructional materials for remedial teaching, debriefing meeting records, reflective reports on teaching, and focus group interview data. These data were organized for each participant and further sorted by date. In the data analysis, all the documents were first read to identify the responses or elements related to the three research questions. Second, all the filtered data for each question were examined in detail to identify themes or categories, followed by classification of the responses or elements based on these categories. Finally, all the themes or categories were compiled to obtain an overall picture.

\section{RESULTS}

The results are presented in the order to answer the three research questions.

\section{A. Reasons for Using Technology}

After we analyzed the participants' statements about their reasons for using technology in remedial instruction, three major reasons were found.

First, because it is well-known that remedial students often lack learning motivation, many participants wrote that they used technology to increase student motivation or interest. For example, S5 stated, "Animations, pictures, and variations in color would draw students' attention."

Second, the participants suggested that using technology was helpful to promoting a complete understanding of a text. For example, S8 specified, "Using video not only helps students grasp the main ideas of a text but also develop a mental picture of the story."

Third, the participants reported that they used technology to save time. For example, S9 claimed, "Using slides to 
present correct answers saves time otherwise spent for writing on a blackboard." S6 also wrote, "It is easy for students to understand the meanings of abstract expressions by showing concrete pictures. Moreover, electronic presentation helps teachers make the best use of class time because writing on a blackboard is conserved."

In summary, the teacher candidates were able to make the best use of technology in instruction to increase motivation, capture attention, make abstract expressions more concrete, integrate different parts of a text, display correct answers, and save the time required for writing on a blackboard. Nevertheless, these applications are mainly teacher-centered, with one-way delivery, and focus on instructional requirements rather than learning needs.

\section{B. Characteristics of Technology Use}

After we analyzed the instructional materials designed by the participants, four themes were identified.

First, multimedia was the most commonly used technology. As mentioned earlier, the participants assumed that animations and pictures would draw students' attention and make abstract expressions more comprehensible. For example, S6 employed interesting pictures to reveal the meanings of difficult Chinese phrases, as displayed in Fig. 1.

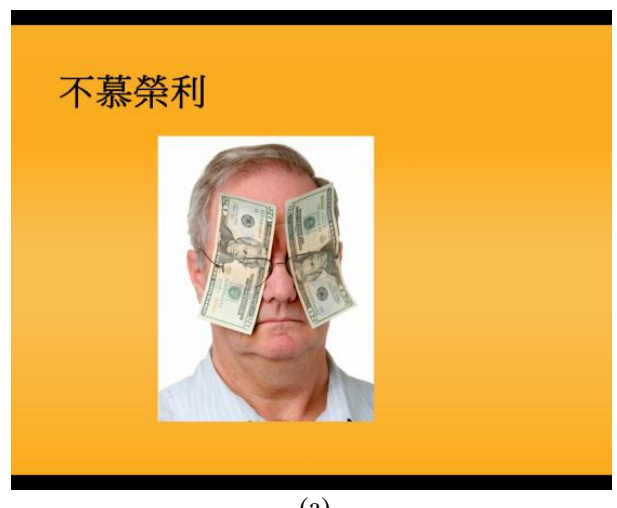

(a)

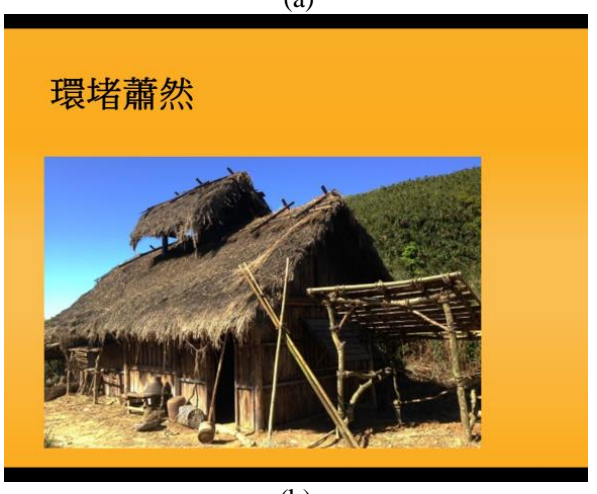

(b)

Fig. 1. PowerPoint slides designed by S6.

Second, the participants liked using Internet resources to provide additional information in teaching. It appeared that teacher candidates were highly capable of searching for related instructional materials on the Internet. Knowing that most of the remedial students had already read material in regular classes, the participants attempted to do something different with these students during remedial instruction. For example, S5 used Google maps while teaching the lesson, "Remember the Night" and displayed Su Shi's derogated routes to help students relate to the challenges and difficulties faced by Su Shi (Fig. 2).

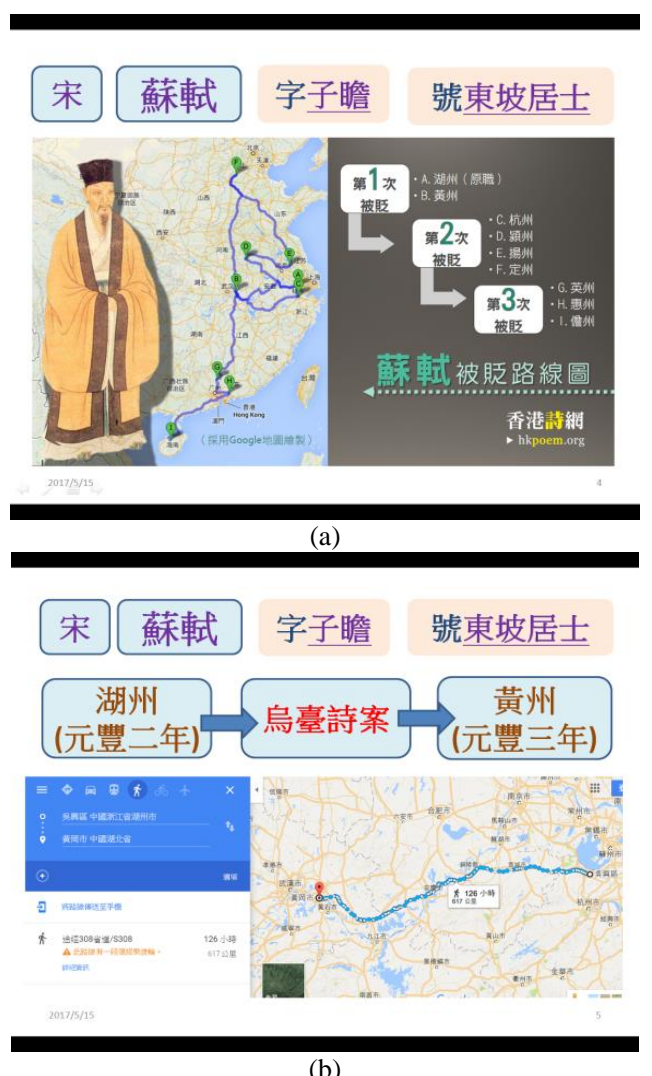

Fig. 2. PowerPoint slides designed by S5.

Third, the participants tended to duplicate the remedial teacher's use of technology in a class. Perhaps these participants did not have sufficient confidence for using technology due to lack of teaching experience. For example, S5 noticed that Miss W drew a box to highlight the important area of a text, as displayed in Fig. 3. Thus, S5 did the same thing when she taught the class, as displayed in Fig. 4.

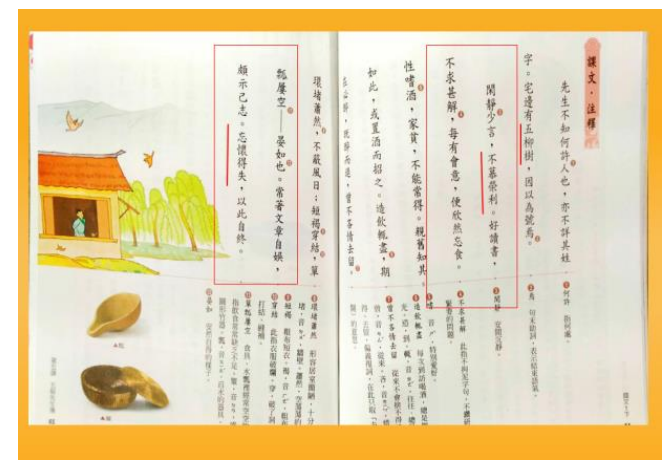

Fig. 3. PowerPoint slides designed by Miss W.

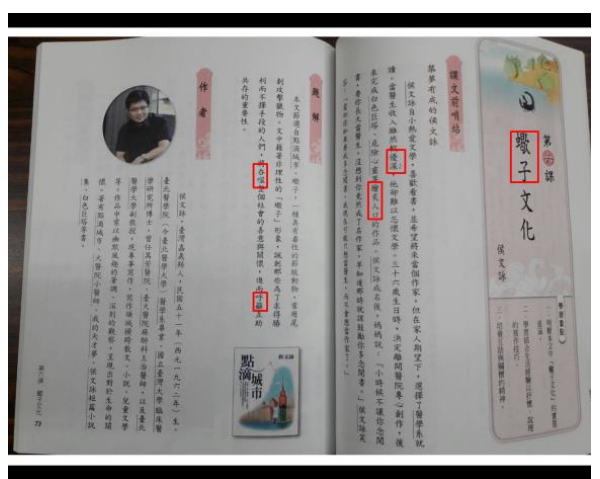

Fig. 4. PowerPoint slides designed by S5. 
S5 also imitated Miss. W in her display of correct answers on the screen. Nevertheless, she added animations, as displayed in Fig 5.

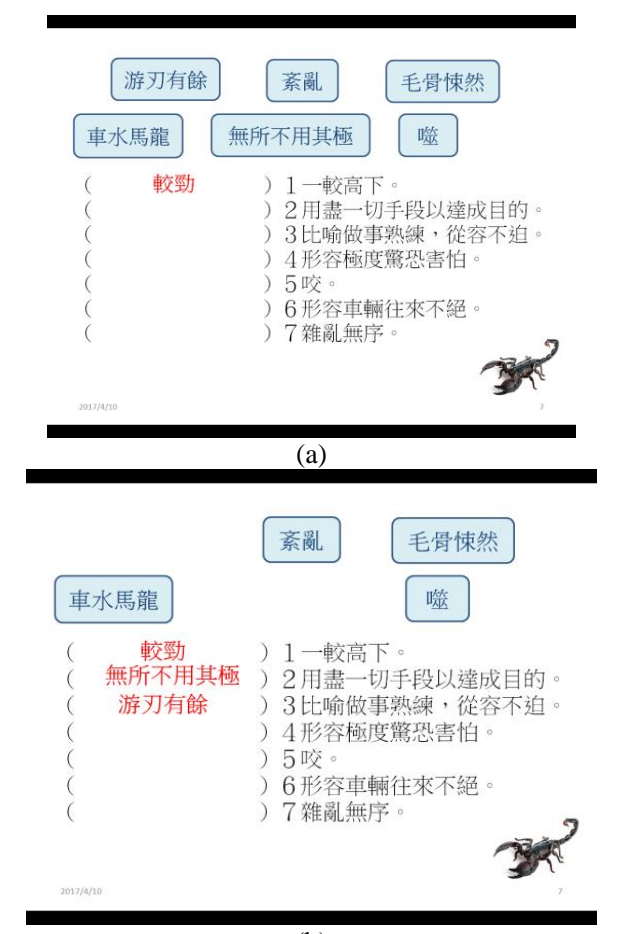

(b)

Fig. 5. PowerPoint slides designed by S5.

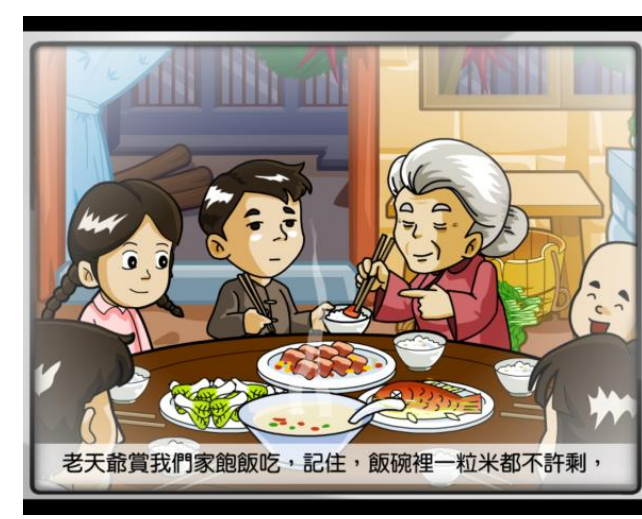

(a)
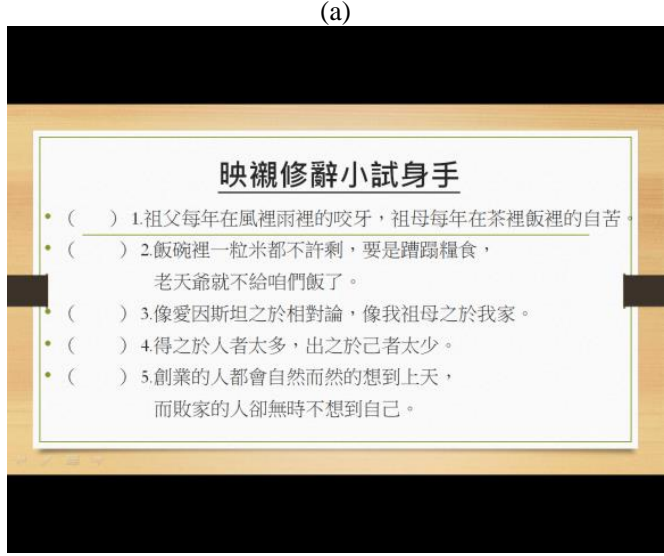

(b)

Fig. 6. PowerPoint slides displayed by S1.

Finally, the participants' use of technology was greatly influenced by their teaching experience. Some of the participants were substitute teachers at secondary schools. These participants had their own opinions concerning how to use technology. For example, S1 indicated that unlike regular classes, remedial classes had no time pressure. Therefore, she suggested, "We can use many pictures and videos to stimulate students' interest. In a word, let the class be more fun" (Interview 20170606). S1 used animations and slides provided by a bookseller when she was teaching the remedial class, as displayed in Fig. 6.

By contrast, one participant with substitute teaching experience had a different opinion on the use of technology. Perhaps she was accustomed to using the blackboard. She firmly stated in her mid-term assignment, "It is totally adequate to use worksheets and a blackboard in remedial teaching. There is no need for using any technological tools."

In summary, teacher candidates usually have superior computer skills. However, due to their lack of field experience, they initially feel more secure imitating existing remedial teachers' technology use. With more experience, they gain the confidence to try something new, and the Internet is a good resource. These results are consistent with those of other research [14], [15]. Moreover, we found that prior teaching experience may hinder the use of technology, an issue that deserves further attention from teacher educators.

\section{Reflections from Field Experience}

After we analyzed the participants' reflective reports written after their remedial teaching, four aspects were identified.

First, the participants commented on the design and use of technological tools in their remedial teaching. For example, S8 reconsidered the design and use of slides:

"I used slides to describe Yanzi's story in detail. I should have invited the students interested in the story to read the lines by themselves. Moreover, the story was long and complicated, resulting in too many words on one slide. I did not consider this when I created the slides." (S8 reflective report 20170605)

Second, the participants reflected on how to deal with unexpected situations when using technology. For example, S5 evaluated her use of video:

"The edited video could not be played smoothly due to a format error. Thus, I used the backup files. However, I had to switch back and forth to display the backup files on the projection screen. Furthermore, I had to locate the initial point before playing a video. This wasted time and learning was hampered. When videos could not be played smoothly, I should have select one or two video clips. Otherwise, students lose patience and interest. Furthermore, I put screenshots on the slides beforehand. I might as well have shifted to another approach that involved lecturing first and then asking questions." (S5 reflective report 20170425)

Third, the participants reflected on the use of technology in the future. For example, S6 expressed his expectations as follows:

"Currently, we use technology primarily for content delivery. I expect that curriculum design in the future would allow students to manipulate technology to assist their own learning. 'Learning by doing' has been stressed in recent years. Teachers should teach their students how to search for useful information from the large database in our knowledge-based society and how to make adequate use of Internet search 
engines. Then, it will be easy to learn anything pertaining to any domain in the future. Besides, students can learn anything that they are interested in on their own by using technology." (S6 reflective report 20170328)

Finally, the participants reflected on the "real" purpose of remedial instruction. The remedial students generally had low learning motivation; thus, the teacher candidates tried various ways to stimulate their interest or to get their attention. However, S3 disagreed with this approach. She explained her view as follows:

"I think that remedial teachers face a dilemma. Teachers try very hard to make learning fun and to give remedial students a happy class. However, does it really help them pass examinations? If not, teachers have no choice but to shift back to somewhat painful methods. In a word, teachers want their students to study happily as well as pass examinations successfully. It seems impossible to reconcile these objectives." (Interview 20170606)

S5 also shared his experience and expressed the following:

"Although activities are fun and stimulate students" participation, they do not necessarily result in learning. The most important thing is to help students learn. You need to understand students thoroughly and identify the obstacles preventing them from learning." (Interview 20170606)

In summary, field experience promoted the teacher candidates to consider more factors when using technology, such as student characteristics, curriculum objectives, time management, and environmental constraints [16]. Therefore, the teacher candidates' competence regarding technology integration into instruction did increase after the field learning because they were able to consider the context while using technology [17].

\section{CONCLUSION}

We arranged field learning as part of the "Remedial Instruction" course offered by our teacher education program. The results indicate that the teacher candidates' use of technology in remedial instruction was affected by their personal opinions of technology and their prior teaching experience. Furthermore, the teacher candidates often imitated the remedial teacher's use of technology during field learning. Electronic presentations and videos were the most frequently used type of technology. Such applications mainly represented one-way delivery of instructional materials. Through field learning, the teacher candidates became more concerned about the main purpose of remedial instruction, reflected on their use of technology in the remedial class, and expected a shift from "teacher presentation" to "facilitating students' self-learning" in the future.

The results from this study suggest the design of the "Remedial Instruction" course involving opportunities for teacher candidates to undergo field learning in addition to attending lectures so that they are able to see the reality of remedial instruction. Furthermore, remedial teachers who can use technology creatively should act models for teacher candidates to imitate. Moreover, encouraging teacher candidates to reflect on their field experience is crucial. Finally, how a teacher educator should provide teacher candidates with positive filed experiences and how the educator should systematically assist teacher educators to maximize their professional growth through field experience requires further investigation.

\section{REFERENCES}

[1] Y. F. Chang, C. L. Hsu, and Y. R. Chen, "Effective use of online video cases in a technology course for pre-service teachers," in Proc. 2011 3rd International Conference on Education Technology and Computer, pp. 49-53, vol. 3, 2011.

[2] R. Jamieson-Proctor, G. Finger, and P. Albion, "Auditing the TK and TPACK confidence of pre-service teachers: Are they ready for the $21 \mathrm{st}$ century?" Australian Educational Computing, vol. 25, no. 1, pp. 8-17, September 2010

[3] T. Brush et al., "Lessons from the field: Integrating technology into preservice teacher education," Journal of Computing in Teacher Education, vol. 17, no. 4, pp. 16-20, 2001.

[4] P. Hernandez-Ramos and C. A. Giancarlo, "Situating teacher education: From the university classroom to the "real' classroom," Journal of Computing in Teacher Education, vol. 20, no. 3, pp. 121-128, 2004

[5] L. Darling-Hammond, "Constructing 21st-centry teacher education," Journal of Teacher Education, vol. 57, no. 3, pp. 300-314, 2006.

[6] I. v. Bargen, "A new reform in teacher education? A historical perspective on recent developments in teacher education in Germany," Research in Teacher Education, vol. 4, no. 2, pp. 5-10, 2014.

[7] B. J. Fwu and Y. R. Hwang, "Field-based experience: A solution for the theory-practice divide in teacher education?" Journal of Research in Education Sciences, vol. 61, no. 2, pp. 57-84, 2016.

[8] Ministry of Education (2013). The regulations of professional courses and credits for pre-service teacher education. [Online]. Available: http://edu.law.moe.gov.tw/LawContentDetails.aspx?id=GL001133\& KeyWordHL=\%E6\%95\%99\%E8\%82\%B2\%E5\%B0\%88\%E6\%A5\% AD\&StyleType $=1$

[9] I. M. Flores, "Developing preservice teachers' self-efficacy through field-based science teaching practice with elementary students," Research in Higher Education Journal, vol. 27, pp. 1-19, 2015.

[10] S. W. Pu, "A study of designing and implementing field learning in teacher preparation," Educational Forum of Soochow University, vol. 4, pp. 99-125, 2015

[11] S. Dexter and E. Riedel, "Why improving preservice teacher educational technology preparation must go beyond the college's walls," Journal of Teacher Education, vol. 54, no. 4, pp. 334-346, 2003.

[12] F. Paraskeva, H. Bouta, and A. Papagianna, "Individual characteristics and computer self-efficacy in secondary education teachers to integrate technology in educational practice," Computers \& Education, vol. 50, no. 3, pp. 1084-1091, 2008.

[13] Ministry of Education. (2012). Training programs for remedial teachers at primary and secondary schools. [Online]. Available: https://tted.cher.ntnu.edu.tw/?p=476

[14] S. Pamuk, "Understanding preservice teachers' technology use through TPACK framework," Journal of Computer Assisted Learning, vol. 28 no. 5, pp. 425-439, 2012.

[15] M. K. Williams, T. S. Foulger, and K. Wetzel, "Preparing preservice teachers for 21st century classrooms: Transforming attitudes and behaviors about innovative technology," Journal of Technology and Teacher Education, vol. 17, no. 3, pp. 393-418, 2009.

[16] J. M. Rosenberg, and M. J. Koehler, "Context and technological pedagogical content knowledge (TPACK): A systematic review," Journal of Research on Technology in Education, vol. 47, no. 3, pp 186-210, 2015.

[17] K. Dawson and A. Norris, "Preservice teachers' experiences in a K-12/ University technology-based field initiative: Benefits, facilitation, constraints, and implications for teacher education," Journal of Computing in Teacher Education, vol. 17, no. 1, pp. 4-12, 2000.

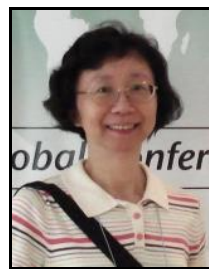

Ya-Fung Chang was born in Taichung, Taiwan. She obtained a bachelor of education from National Taiwan Normal University, Taiwan. Then she taught English in a junior high school. Two years later, she went to America for graduate study. She obtained a master's Degree in educational technology from University of Northern Colorado, U.S.A. in 1984, and a $\mathrm{Ph}$. D. in secondary education from University of Illinois (Champaign-Urbana), U.S.A. in 1987. 
She is currently a professor at Center for Teacher Education at Tamkang University, New Taipei City, Taiwan. She has been working at the center for more than twenty years. The courses she teaches are Instructional Media and Applications, Curriculum Development and Design, Class Management, and so on. She was the director of the center from the year of 2000 to 2004 Her research interest is in technology integration in teacher education, and she writes many related articles.

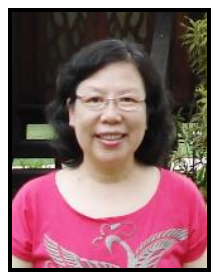

Chia-ling Hsu was born in Taipei, Taiwan. She graduated from Soochow University, Taipei, Taiwan. She obtained a master's degree in computer education from Columbia University, U.S.A. in 1983, and a Ph.D. in curriculum and instructional design from Missouri University U.S.A. in 1993. She is currently an associate professor and the director of the Center for Teache Education at Tamkang University, New Taipei City,
Taiwan. The courses she teaches are Instructional Media and Applications, Instructional Theories, and so on. She published many articles related to instructional design and e-learning.

Wei-Nian Chen is a graduate student at the Department of Chinese Literature, Tamkang University, New Taipei City, Taiwan. He was a teacher candidate at our secondary teacher education program two years ago. He is currently a research assistant on this project.

Tzu-Ting Wang is a graduate student at Graduate Institute of Curriculum and Instruction, Tamkang University, New Taipei City, Taiwan. Her college major was English. She is currently a teacher candidate at our secondary teacher education program. She is also a research assistant on this project. 